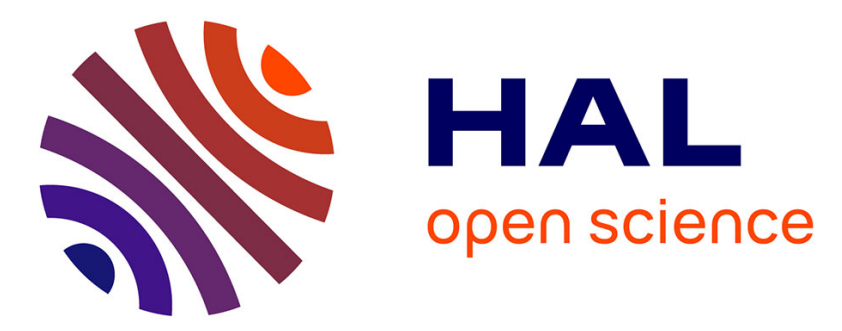

\title{
Public Accountability ICT Support: A Detailed Account of Public Accountability Process and Tasks
}

Rui Pedro Lourenço, Suzanne Piotrowski, Alex Ingrams

\section{To cite this version:}

Rui Pedro Lourenço, Suzanne Piotrowski, Alex Ingrams. Public Accountability ICT Support: A Detailed Account of Public Accountability Process and Tasks. 14th International Conference on Electronic Government (EGOV), Aug 2015, Thessaloniki, Greece. pp.105-117, 10.1007/978-3-31922479-4_8. hal-01412240

\section{HAL Id: hal-01412240 \\ https://hal.science/hal-01412240}

Submitted on 8 Dec 2016

HAL is a multi-disciplinary open access archive for the deposit and dissemination of scientific research documents, whether they are published or not. The documents may come from teaching and research institutions in France or abroad, or from public or private research centers.
L'archive ouverte pluridisciplinaire HAL, est destinée au dépôt et à la diffusion de documents scientifiques de niveau recherche, publiés ou non, émanant des établissements d'enseignement et de recherche français ou étrangers, des laboratoires publics ou privés. 


\title{
Public accountability ICT support: a detailed account of public accountability process and tasks
}

\author{
Rui Pedro Lourenço ${ }^{1,2}$, Suzanne Piotrowski ${ }^{3}$, Alex Ingrams $^{3}$ \\ ${ }^{1}$ INESC Coimbra, Portugal \\ ${ }^{2}$ Faculty of Economics, University of Coimbra, Portugal \\ \{ruilouredfe.uc.pt\} \\ ${ }^{3}$ School of Public Affairs and Administration, Rutgers University-Newark, USA \\ \{spiotrowescarletmail.rutgers.edu\} \\ \{alex.ingrams@gmail.com\}
}

\begin{abstract}
A key objective of open government programs is to promote public accountability by using Information and Communication Technologies (ICT) to release data on the internal working of public agencies. However, it is not clear how actual accountability (such as sanctions or rewards) may be achieved from the data disclosed. Nor it is clear how ICT in general should support it. To better understand how ICT can support open data initiated accountability processes in achieving their goal, this paper considers the three phases (information, discussion, and consequences) usually used to describe such processes. Defining ICT support for these major phases is a difficult effort, since each phase encompasses different tasks and support requirements. This paper aims to address this problem by providing a detailed account of the tasks associated with the whole public accountability process. This may be used by those responsible for open government programs to design and deploy comprehensive ICT support platforms using a task-technology fit perspective.
\end{abstract}

Keywords: Open Government; Accountability; ICT; Task-Technology Fit.

\section{Introduction}

A central pillar of open government initiatives is the active disclosure of data held by public agencies. The creation of open data portals (e.g. Data.gov) has subsequently become associated with the expression Open Government Data (OGD). In the context of open government, the release of data might serve two main purposes [1]: 1) allowing the re-use of such data to enable the creation of new products and services by the private sector; or 2), transparency for accountability, where public agencies disclose data about their internal works allowing the general public to monitor their actions and performance [2], [3].

Despite the apparent success and high impact of open data portals, Yu and Robinson [4] draw attention to the ambiguity of the expression Open Government Data as it may convey two very different meanings: 1) the disclosure of politically relevant data, whether or not using information technology or 2) the usage of technological plat-

adfa, p. 1, 2011.

(C) Springer-Verlag Berlin Heidelberg 2011 
forms to facilitate access to government held data, whether or not politically relevant. $\mathrm{Yu}$ and Robinson [4] also point out that these initiatives focus "more on technological innovation and service delivery" and public agencies "have tended to release data that helps them serve their existing goals without throwing open the doors for uncomfortable increases in public scrutiny."

Despite the doubts raised by Yu and Robinson [4], OGD portals may be considered as an example of how ICTs may support public accountability. Even so, as Bovens [5] notes, transparency as data disclosure is certainly a pre-requisite for public accountability but the latter also requires the scrutiny of the data provided and the possibility to award rewards or sanctions accordingly. Therefore, OGD portals could, at most, be considered as a technology that supports the initial phase (data disclosure) of the whole public accountability process which comprises three main phases: information/transparency, debate, and consequences.

The discussion on how ICTs might help to support public accountability needs to look beyond OGD portals and data disclosure, and a Task-Technology Fit (TTF) [6] perspective may be useful to frame such discussion. TTF was advanced in the context of Computer-Mediated Communications (CMC) and Group Support Systems (GSS) to stress the importance and impact of a good fit between the task to be performed by groups and technologies used, on the effectiveness of group support (CMC, GSS). To determine a 'good fit' it is necessary to consider both the attributes of task(s) to be performed and the relevant technology characteristics.

The problem of finding the 'best fit' technologies to support public participation, in part or as a whole process, is also illustrated by Robinson, Yu, Zeller, and Felten [7] who, when describing a set of ICT tools that have the potential to support data presentation and visualization, ended their analysis with this sentence: "Exactly which of these features to use in which case, and how to combine advanced features with data presentation, is an open question." To design a complete public accountability platform that goes beyond simple data disclosure it is necessary to consider:

- What tasks need to be supported along the whole public accountability process?

- What type of support is required for each task?

- What kind of applications have the potential to support each task?

- How to design, develop and implement a comprehensive public accountability platform by selecting and combining the 'best fit' applications and technologies to meet the requirements?

We identify and characterize the tasks performed in the context of a public accountability process (providing an answer to the first question) and therefore provide the solid ground upon which a TTF approach might be used. We start by characterizing public accountability (section 2), including its main phases and parties involved. In section 3 , the three main phases of the public accountability process are further analyzed and divided into discrete tasks according to the literature. Within section 4 , we identify a set of abstract data patterns performed along the process which already indicate the type of ICTs adequate to support them. By the end of section 4, each public accountability task is associated with one or more abstract task patterns thus 
providing a starting point to design a comprehensive public accountability support platform under a TTF approach.

\section{Public accountability}

The concept of accountability is complex ("an ever-expanding concept" [8]) and is subject to many interpretations and disagreement about its meanings [9]-[11]. Several authors have advanced definitions of accountability [5], [12], [13], and have proposed accountability typologies [5], [12], [14], [15] (see also Steccolini [16, p. 332] - Table 1 for a list of such typologies). In this paper we will consider Bovens' definition:

"Accountability is a relationship between an actor and a forum, in which the actor has an obligation to explain and to justify his or her conduct, the forum can pose questions and pass judgement, and the actor may face consequences." [5]

Moreover, our focuses is on public accountability, that is, the accountability of organizations or officials exercising public authority, from a perspective concerned with democratic control over those institutions and individuals [5]. Fig. 1 illustrates the simplified accountability model considered here (inspired by [5], p. 454 - Figure 1), depicting the main stages and main parties involved in public accountability process.

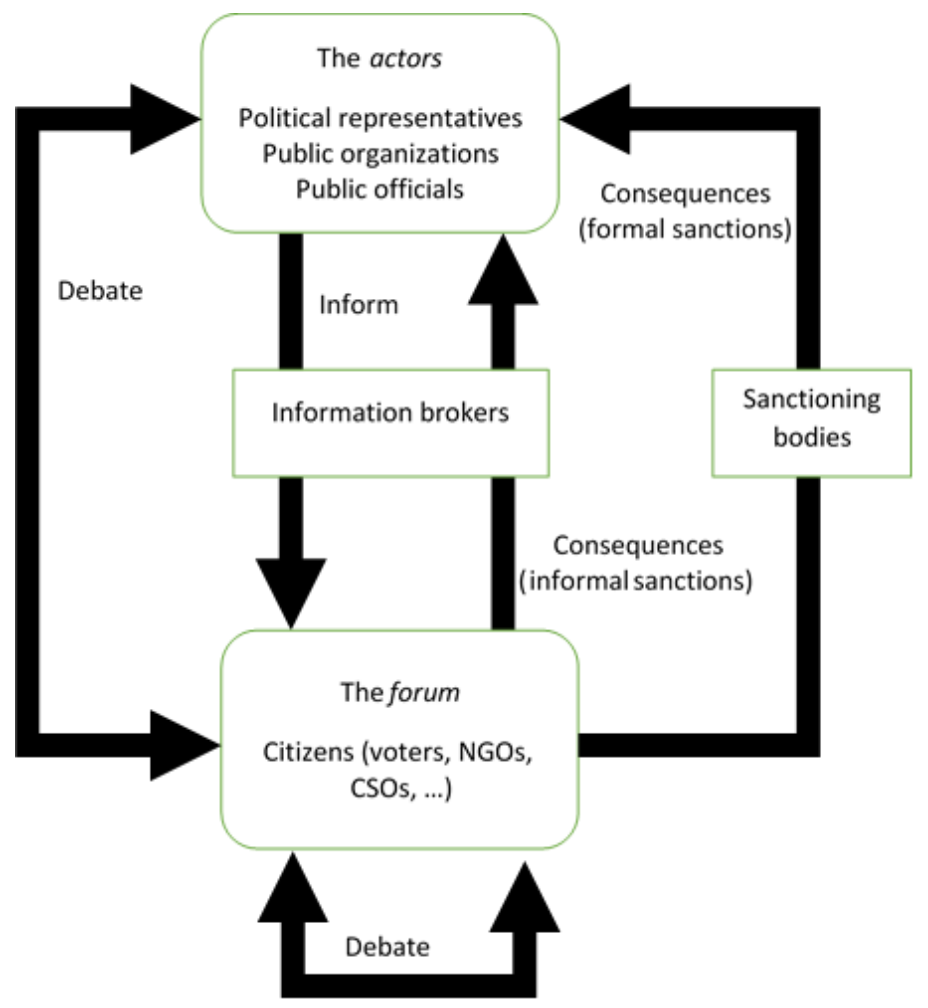

Fig. 1. Public accountability model considered (inspired by [5], p. 454 - Figure 1). 
The main stages depicted in Fig. 1, usually considered in any public accountability processes [5], [17], are:

1. Information, sometimes also equated to transparency [18] or data disclosure, where the 'actor' discloses the information needed to account for its actions ("to explain and to justify his or her conduct");

2. Debate, during which the information gathered is processed by the 'principal' [10], who has the right to ask for additional information and justifications under the principle of 'answerability' [18];

3. Consequences, during which the 'principal' passes judgment based on the information analyzed, and decides whether or not to sanction or reward the 'actor' for his or her actions.

Fig. 1 also depicts the main parties involved in public accountability. Representative democracies may be considered as "a concatenation of principal-agent relationships"[19] between citizens (the forum), their elected political representatives, and public officials (the actor) to whom actual administrative actions are delegated and who have an obligation to account for their actions to whom they represent. However, not all accountability relationships derive from this principal-agent principle. The fragmentation of the public sector as a result of the adoption of new public management (NPM) policies [20], for instance, led to an increase in the complexity of these chains of delegation which effectively turn into 'networks' or 'webs' of accountability [19], [20]. These may include entities from "third-party government" [15], "decentralised agencies" [21] or semi-autonomous agencies [13] to whom the full principal-agent relationship may not apply, thus giving origin to horizontal and diagonal types of accountability [5], [13].

Even if we might consider citizens as the 'ultimate public accountability forum' and public agencies, public officials and political representatives as the general actor, we must also consider the role of other parties. As an example, while courts might not fit directly into this 'actor'-'forum' accountability relationship, they might be crucial for citizens to effectively apply legal sanctions. Information brokers [22], [23] or infomediaries [24] such as the media, CSOs or NGOs may also play an important role in accountability relations by helping to collect data, process it and produce information in a format ordinary citizens find easy to understand, or to reinforce the influence of indirect, informal sanction mechanisms such as 'blame and shame' [10], [13], [18].

\section{The process of public accountability and its tasks}

From the macro view of the accountability process presented in the last section, it is possible, by analyzing accountability related literature, to break it down into more discrete tasks. We identified eleven such tasks:

1. Voluntary disclosed data. To address the forum's "direct and passive information rights" [10], actors need to voluntarily and proactively [18] disclose ac- 
countability related data. The data organization should facilitate analysis and reusability according to the objectives of open government [1].

2. Requested and disclosed data. Voluntarily disclosed data might not be sufficient for forums to hold public agents accountable. Forums may therefore need to request additional data from public agencies according to "demand-driven access" to information [18].

3. Data from other sources. But even when public agencies make available additional data as a response to requests from the accountability forum, it still may not be sufficient. Therefore it may be necessary for the forum to collect data from other sources. This task can include searching for data, collecting data in hard copy and converting it to digital format [25], collecting data in digital format from other sources, or even asking third-parties (such as audit offices) to disclose it.

4. Distribute and increase visibility of data. Peixoto [26] explicitly refers to the "publicity condition" (publicized transparency) which implies the existence of a free press and a facilitated access to the internet as a preferred means to distribute information. While these publicity conditions exist in contemporary representative democracies, there may still be necessary additional efforts on the part of the accountability forum to further improve data visibility [25] and therefore "reach the intended public" [26].

5. Data quality and suitability. Not all data releases through open government data portals are relevant for accountability [4]. Fox [18] reinforces this perspective and uses the expression "opaque or fuzzy transparency" to designate the "dissemination of information that does not reveal how institutions actually behave", but also "to information that is divulged only nominally, or which is revealed but turns out to be unreliable." Some OGD platforms explicitly state that all disclosed data adheres to some kind of quality assurance policy ${ }^{1}$.

6. Process and merge data. The result of previous tasks is a repository of accountability relevant, complete and high quality data. This task in the accountability process is to organize it, merge it, process it and produce new data and information [25]. This requires accountability forums such as NGOs, CSOs, or ordinary citizens to possess the time, personnel, competence, and technical capabilities to process the available data [10], [26].

7. Interpretation and identification of an issue. The end result of the previous tasks is reliable information. In this task the forum continuously monitors and interprets the information to identify and characterize potential accountability issues. This has been described as arriving "at a shared definition of the problem", including determining "why and how the current situation has arisen" [17].

8. Request additional information and ask for justifications. Having fully characterized the accountability issue, including the identification of the relevant accountability actors involved, it should be possible for the forum to further interro-

1 "All information accessed through Data.gov is subject to the Information Quality Act (P.L. 106-554). ... each agency has confirmed that the data being provided through this site meets the agency's Information Quality Guidelines.” From Data.gov (https://www.data.gov/datapolicy) last visited in 30/10/2014. 
gate the actor and question the legitimacy of conduct [5], ask for additional information [13], pose follow-up questions [11], and demand explanations [18] concerning a specific issue. This task marks the beginning of the debate phase between the forum and the actor [13] which might be considered as a transition between transparency and accountability [18].

9. Clarify and justify. Still part of the debating phase, actors are expected to explain their behavior and justify their actions in response to public reaction and questioning [5], [11], [26].

10. Assess and judge. At some point the debate between the forum and the actor involved in a particular issue should reach an end. All available information is considered by the forum [11] in order reach a concluding judgment about the actor's actions regarding a particular issue under analysis [5], [11].

11. Select and apply sanctions. If there is a decision to sanction the actor, the task is now to select which of the available sanction mechanisms should be used [13].The array of possible options depends on the accountability issue type, the type and nature of the actor, and the nature of the accountability involved.

(a) Negative publicity ('blame and shame'). In the spectrum of accountability sanctions, negative publicity or 'blame and shame' sanctions are considered an indirect and informal sanctioning mechanism [10], [11]. This sanction mechanism might be easier to apply since it depends mostly on the forum's ability to make visible or 'shame' the actor involved. However, in practice, the 'shaming' power depends on how other information brokers, mass media or specialized forum such as policy or public administration networks, deal with and publicize such issues [13], [18]. To reinforce the impact of a sanction mechanism, accountability forums might partner with media to regularly report on the issues, use social media to publicize the sanction in social networks and forums, or use notification mechanisms to increase citizens' awareness.

(b) Seek legal sanctions. When deemed appropriate, the accountability forum might consider the possibility of taking the actor (agency or public official responsible) to court. Again, the success of this sanctioning option would depend on third parties (in this case, the judicial system). Recognizing this, it is considered an indirect sanctioning mechanism [10].

(c) Influence supervisory or sanctioning bodies. Just like the courts, supervisory and sanctioning bodies have the possibility to directly enforce sanctions on public officials and public agencies. Accountability forums may try to indirectly influence these bodies through the press using 'blame and shame' or directly influence them through petitions or research support [25].

(d) Influence hierarchy. One possible 'weak' accountability arrangement available to accountability forums outside the actors' hierarchical structure includes influencing and appealing to agencies or public officials in higher positions to apply sanctions which may include cutting budgets and bonuses, termination of contracts, tightened regulations, fines, discharge of management or increase control and reduce independence [13][11].

(e) Influence political and electoral sanctions. Elections are a powerful sanction mechanism for political representatives who anticipate the retrospective control 
and sanctions of future electoral moments and act in order to maximize their reelection possibilities [27]. In order to effectively apply these types of sanctions, accountability platforms need to increase the impact of "blame and shame' on voters, political parties, campaign donors and alike by keeping an up-to-date record of the issues discussed and decisions reached.

(f) Influence participative forums. Some actors (public agencies) promote internal participatory forums. These might function themselves as accountability forums with privileged access to data and hierarchy, and possibly with the power to impose sanctions directly. In this case, an external accountability platform might function as an internal analysis support tool, or as a way to pressure these forums to initiate accountability processes and impose sanctions.

\section{$4 \quad$ Abstract task patterns}

The tasks presented in the previous section define the high-level requirements to develop a comprehensive accountability support platform. This section aims to contribute to a platform design proposal, inspired by TTF theory and Collaboration Patterns ("classify group activities based on the changes-of-state they produce") [28], by suggesting a set of abstract task patterns already linked to some examples of elementary technologies and applications:

1. Disclose, organize and link data. Traditionally, public agencies have been using their own web sites to publish accountability related data ${ }^{2}$. However, many public agencies now publish in one-stop government data portals such as Data.gov or Data.gov.uk [29].These portals are at the core of what Schillemans, Van Twist et al. [17] designate as "dynamic accountability" which allows citizens to monitor government in near real-time Accountability forums outside governmental control might find it difficult to perform some of the tasks identified previously when using government platforms such as portals, which seems to indicate that 'independent' platforms may be needed. One important aspect to consider is the adoption of the principles of Linked Data: "data published on the Web in such a way that it is machine-readable, its meaning is explicitly defined, it is linked to other external data sets, and can in turn be linked to from external data sets." [30]

2. Rate and categorize (data, issues, and sanctions). There is a need to properly categorize data in order to help distinguish accountability related data (and their different topics) from other type of data that coexist in today's open data government portals. Rating mechanisms might also help to improve the impact and influence of accountability processes on the general public, particularly when there is a time lapse between the moment of discovery and discussion of an issue and the actual sanctioning moment (at elections, for instance). One way to complement official quality assurance and categorization mechanisms finds inspiration in

\footnotetext{
${ }^{2}$ See [38] for a list of online transparency assessment efforts based on individual website analysis.
} 
crowd sourcing - "using the collective wisdom of a large group of people to help solve problems" [31].

3. Notify and increase awareness. Even in high profile open government portals, accountability relevant data may be 'hidden' by the sheer amount of datasets available. It is therefore necessary not only to create specific organizing structures within those general purpose portals [32] to increase this data visibility but also to use awareness mechanisms (such as Real Simple Syndication - RSS - and social networks - e.g. Twitter).

4. Communicate (directed). In some cases open government data portals offer the possibility to request additional datasets (using request forms or email) and even allow users to monitor the request process by providing request status information $^{3}$. Yet in other situations, 'traditional' Freedom of Information Act mechanisms and channels may be used to request such data ${ }^{4}$. Accountability forums and information brokers should facilitate such requests by providing seamless communication channels and independent monitoring of the whole process.

5. Search and discover. Independent platforms run by accountability forums can play a crucial brokerage role by providing a single interface to accept data requests and look for the data or, at least, find out where it can be obtained. Platforms might use crowdsourcing efforts for that purpose, complemented by technical resources like search engines or web crawlers to identify potential databases of interest and thus catalogue data resources.

6. Process data (format and analyze). Business Intelligence and Analytics systems [33] may provide the necessary tools, including Extract, Transform and Load (ETL) capabilities, to produce a data repository adequate for further processing and analysis. In general, accountability platforms (such as governmental portals or those privately maintained) should offer data mining and statistical analysis capabilities including the possibility to build new "mashup" datasets, to build and compare data-based performance indicators or to identify 'peculiar' cases.

7. Decide (issue, sanction and sanction type). Several tasks associated with the accountability process require users from the accountability forum to characterize an emergent issue, to decide whether or not to sanction an actor or to choose from a set of possible sanction types. In a broader context, such tasks might be considered as "Evaluate" and "Build Commitment" tasks of group collaboration efforts [28] or may be referred to, in social media contexts, as "Crowd voting" [31].

8. Discuss and debate. Several tasks require members of the accountability forum to debate among themselves while other tasks would require debating with the involved actors, similar to the divergent phase of groups strategic planning activities [34] and the 'generate' collaborative patterns [28]. These discussions are crucial to identify potential accountability issues, to formulate new questions, or to precede the elaboration of 'blame and shame' documents.

9. Reduce, filter and clarify (issue and question). In some cases, the discussion is just part of a process for defining new issues or new questions to ask accountabil-

\footnotetext{
${ }^{3}$ See, for instance, the New Zealand data portal (https://data.govt.nz/latest-data-requests/)

4 "How do I make a FOIA Request?" (http://www.foia.gov/how-to.html)
} 
ity actors. In this case it is necessary to filter the whole pool of suggestions and ideas (removing inappropriate questions, for instance) and to consolidate similar or redundant ideas into a single one. Care must be taken so that this would not constitute a form of censorship eliminating opposing points of view.

10. Create ('blame and shame' document, legal document, or petition). Producing accountability documents from a divergent pool of ideas resulting from the debate phase is a challenge and it is considered the "convergent" part of any group cognitive task [34]. In general, web collaborative writing tools such as wikis might provide support for this task, while blikis [35] may provide a bridge between the discussion (divergent) phase and the collaborative writing (convergent) phase.

11. Manage progress (issues, legal processes). When the forum decides that sanctions should be awarded in the form of a legal process, it is important to know at each moment and for each legal process, what its status is. To accomplish this, workflow systems or issue tracking systems (used in software engineering, for instance) might be adopted.

12. Obtain specialized resources. Throughout the accountability process several tasks require resources, such as specialized skills and competences or financial resources, which an isolated citizen might not possess. To support the forum in obtaining such resources (and account for their usages), the accountability platform can adopt crowdsourcing tools.

13. Supporting the overall process: facilitation. In group settings, facilitation is understood as "a set of functions or activities carried out before, during, and after a meeting to help the group achieve its own outcomes" [36]. It may be performed without any technology support ("human facilitation"), solely by technology ("automated facilitation"), or by human facilitators with technological support [37].

Table 1 links each accountability task and process stage with several predominant abstract task patterns. Together with the illustrative technology examples provided, this detailed account of abstract task patterns occurring during the complete public accountability process forms a contribution to a tentative support platform design proposal. The abstract task patterns proposed above are now more easily associated with particular supporting technologies in a TTF perspective and provide an answer to the first two questions elaborated in the Introduction section.

\section{Conclusion}

The potential of Information and Communication Technologies (ICT) to support democratic processes (eDemocracy) and governmental service provision (eGovernment) has been recognized for quite some time now. Recently, scholars and practitioners have turned their attention to open government and, specifically, to governmental transparency and public accountability. Open government efforts led to the creation of dataset portals such as data.gov which enable open data initiated accountability processes. 
Table 1. Stages, tasks and abstract task patterns in the public accountability process

\begin{tabular}{lll}
\hline Stages & Tasks & Abstract task patterns \\
\hline Information & 1 & 1 \\
& 2 & 4,1 \\
& 3 & $5,6,1$ \\
& 4 & 1,3 \\
Debate/Discuss & 5 & 2 \\
& 6 & 6,1 \\
& 7 & $8,9,7,11$ \\
Consequences & 9 & $8,9,4$ \\
& 10 & 4 \\
& 11 & 8,7 \\
& $11 . \mathrm{a}$ & $10,2,3$ \\
& $11 . \mathrm{b}$ & $12,10,11,3$ \\
& $11 . \mathrm{c}$ & 10,3 \\
& $11 . \mathrm{d}$ & 10,3 \\
& $11 . \mathrm{e}$ & $10,2,3$ \\
& $11 . \mathrm{f}$ & $6,10,3$ \\
\hline
\end{tabular}

The internet and social media applications, for instance, have also been generically recognized as having the potential to support data disclosure and dissemination, and public debate. But this recognition does not take into account all accountability process stages, or the specific requirements of each stage. To go beyond such generic descriptions of the ICT potential to support public accountability it is necessary, first and foremost, to have a detailed and comprehensive account of the tasks performed by the different parties involved in the process. Only then a Task-Technology Fit approach might be used to select the appropriate technology or application needed to support each individual task and therefore, provide a comprehensive public accountability support platform.

This paper contributes to the design of a comprehensive public accountability support platform by considering the three main stages of the accountability process and, supported by relevant research literature, details them into more specific tasks. Then, inspired by the collaboration patterns used to support group tasks, identifies a set of abstract task patterns occurring along the accountability process whose description is now suitable for a Task-Technology Fit approach. As such, this work answers the first two questions elaborated in the Introduction section. Further research is needed to fully answer the remaining two questions, and it is expected that scholars and practitioners use the proposed detailed account of a public accountability process as a solid foundation to design and develop comprehensive accountability support platforms.

Acknowledgements. This work has been partially supported by the Fundação para a Ciência e a Tecnologia (FCT) under project grant UID/MULTI/00308/2013. 


\section{References}

1. D. Linders and S. C. Wilson, "What is Open Government? One Year after the Directive," in 12th Annual International Conference on Digital Government Research (Dg.o'11), 2011, pp. 262-271.

2. S. Grimmelikhuijsen, G. Porumbescu, B. Hong, and T. Im, "The Effect of Transparency on Trust in Government: A Cross-National Comparative Experiment," Public Adm. Rev., vol. 73, no. 4, pp. 575-586, 2013.

3. A. Meijer, "Understanding the Complex Dynamics of Transparency," Public Adm. Rev., vol. 73, no. 3, pp. 429-439, 2013.

4. H. Yu and D. Robinson, "The New Ambiguity of 'Open Government," UCLA Law Rev. Discl., vol. 59, pp. 178-208, 2012.

5. M. Bovens, “Analysing and Assessing Accountability: A Conceptual Framework," Eur. Law J., vol. 13, no. 4, pp. 447-468, 2007.

6. I. Zigurs and B. K. Buckland, "A Theory of Task/Technology Fit and Group Support Systems Effectiveness," MIS Q., vol. 22, no. 3, pp. 313-334, 1998.

7. D. Robinson, H. Yu, W. P. Zeller, and E. W. Felten, "Government Data and the Invisible Hand," Yale J. Law Technol., vol. 11, p. 160, 2009.

8. R. Mulgan, “'Accountability': An Ever-Expanding Concept?,” Public Adm., vol. 78, no. 3, pp. 555-573, 2000.

9. J. G. S. Koppell, "Pathologies of Accountability: ICANN and the Challenge of 'Multiple Accountabilities Disorder,"” Public Adm. Rev., vol. 65, no. 1, pp. 94-108, 2005.

10. J. Biela and Y. Papadopoulos, "Strategies for Assessing and Measuring Agency Accountability," in Conference Paper presented at the 32nd European Group for Public Administration (EGPA) Annual Conference. Toulouse, France: September, 2010.

11. G. J. Brandsma and T. Schillemans, "The Accountability Cube: Measuring Accountability," J. Public Adm. Res. Theory, 2012.

12. A. Sinclair, "The chameleon of accountability: forms and discourses," Accounting, Organ. Soc., vol. 20, no. 2/3, pp. 219-237, 1995.

13. T. Schillemans, "Accountability in the Shadow of Hierarchy: The Horizontal Accountability of Agencies," Public Organ. Rev., vol. 8, no. 2, pp. 175-194, 2008.

14. R. D. Behn, Rethinking democratic accountability. Washington, DC: Brookings Institution Press, 2001.

15. M. J. Dubnick and H. G. Frederickson, "Accountable agents: federal performance measurement and third-party government," J. Public Adm. Res. Theory, vol. 20, no. suppl 1, pp. i143-i159, 2010.

16. I. Steccolini, "Is the Annual Report an Accountability Medium? An Empirical Investigation into Italian Local Governments," Financ. Account. Manag., vol. 20, no. 3, pp. 327-350, 2004.

17. T. Schillemans, M. Van Twist, and I. Vanhommerig, "Innovations in Accountability," Public Perform. Manag. Rev., vol. 36, no. 3, pp. 407-435, 2013.

18. J. Fox, "The uncertain relationship between transparency and accountability," Dev. Pract., vol. 17, no. 4-5, pp. 663-671, 2007.

19. M. Bovens, D. Curtin, and P. 't Hart, "Towards a More Accountable EU: Retrospective and Roadmap," Amsterdam Centre for European Law and Governance, 2010.

20. C. Scott, "Accountability in the Regulatory State," J. Law Soc., vol. 27, no. 1, pp. 38-60, 2000 .

21. M. Busuioc, "Accountability, Control and Independence: The Case of European Agencies,” Eur. Law J., vol. 15, no. 5, pp. 599-615, 2009. 
22. B. A. Rutherford, "Developing a conceptual framework for central government financial reporting: intermediate users and indirect control," Financ. Account. Manag., vol. 8, no. 4, pp. 265-80, 1992.

23. D. Heald, "Fiscal transparency: concepts, measurement and UK practice," Public Adm., vol. 81, no. 4, pp. 723-759, 2003.

24. B. Carter, "Transparency and accountability," GSDRC, 2014.

25. A. van Zyl, "How Civil Society Organizations Close the Gap between Transparency and Accountability," Governance, vol. 27, no. 2, pp. 347-356, 2014.

26. T. Peixoto, "The Uncertain Relationship Between Open Data and Accountability: A Response to $\mathrm{Yu}$ and Robinson's The New Ambiguity of 'Open Government'*," UCLA Law Rev. Discl., vol. 60, pp. 200-213, 2013.

27. J. Elster and A. Przeworski, "Introduction," in Deliberative Democracy, J. Elster, Ed. Cambridge: Cambridge University Press, 1998, pp. 1-18.

28. R. Briggs, G. Kolfschoten, V. Gert-Jan, and D. Douglas, "Defining key concepts for collaboration engineering," in Twelfth Americas Conference on Information Systems (AMCIS 2006), 2006, p. 17.

29. E. Kalampokis, E. Tambouris, and K. Tarabanis, "A classification scheme for open government data: towards linking decentralized data," Int. J. Web Eng. Technol., vol. 6, no. 3, pp. 266-285, 2011.

30. C. Bizer, T. Heath, and T. Berners-Lee, "Linked data - the story so far," Int. J. Semant. Web Inf. Syst., vol. 5, no. 3, pp. 1-22, 2009.

31. J. Pedersen, D. Kocsis, A. Tripathi, A. Tarrell, A. Weerakoon, N. Tahmasbi, X. Jie, D. Wei, O. Onook, and G. J. de Vreede, "Conceptual Foundations of Crowdsourcing: A Review of IS Research,” in System Sciences (HICSS), 2013 46th Hawaii International Conference on, 2013, pp. 579-588.

32. R. P. Lourenço, "Open Government Portals Assessment: A Transparency for Accountability Perspective," in Electronic Government, vol. 8074, M. Wimmer, M. Janssen, and H. Scholl, Eds. Springer Berlin Heidelberg, 2013, pp. 62-74.

33. C. Hsinchun, R. H. L. Chiang, and V. C. Storey, "Business Intelligence and Analytics: from Big Data to Big Impact," MIS Q., vol. 36, no. 4, pp. 1165-1188, 2012.

34. R. Orwig, H. Chen, D. Vogel, and J. F. Nunamaker, "A multi-agent view of strategic planning using group support systems and artificial intelligence," Gr. Decis. Negot., vol. 6, no. 1, pp. 37-59, 1997.

35. R. P. Lourenço, "A bliki model to support political discourse formation," in 2008 international symposium on Wikis (WikiSym '2008), 2008.

36. R. P. Bostrom, R. Anson, and V. K. Clawson, "Group facilitation and group support systems," Group support systems: New perspectives, no. 8. Macmillan, New York, pp. 146-168, 1993.

37. I. Seeber, R. Maier, and B. Weber, "Opening the Black Box of Team Processes and Emergent States: A Literature Review and Agenda for Research on Team Facilitation," in System Sciences (HICSS), 2014 47th Hawaii International Conference on, 2014, pp. 473482.

38. R. P. Lourenço, "Data disclosure and transparency for accountability: A strategy and case analysis," Inf. Polity, vol. 18, no. 3, pp. 243-260, 2013. 